\title{
Mango Seed Oil
}

National Cancer Institute

\section{Source}

National Cancer Institute. Mango Seed Oil. NCI Thesaurus. Code C107327.

The oil extracted from the kernel of Mangifera indica. Mango seed oil is typically used in skincare preparations. 